\title{
Identification and Characterization of Bioactive Compounds of Leaves of Justicia Gendarussa Burm. F.
}

\author{
G. Shamili ${ }^{1}$ and G. Santhi ${ }^{2} *$ \\ ${ }^{1,2}$ PG and Research Dept. of Botany, Kunthavai Naacchiyaar Govt. Arts College for Women, Thanjavur, India
}

Available online at: www.isroset.org

Received: 20/Dec/2018, Accepted: 10/Jan/2019, Online: 28/Feb/2019

\begin{abstract}
The present investigation has been carried out to find the phytochemicals present in Justicia gendarussa leaves extract. The leaves of Justicia gendarussa were collected from Kadukaval in January 2018 Thanjavur, Tamil Nadu, India. The powder leaf was extracted with aqueous and $70 \%$ methanol for 24 hours and studied for FTIR, HPLC and NMR. A preliminary phytochemical testing of the leaves extract where than to identify the phytoconstiuents, which reveals that presence of tannin, saponin, flavonoids, steroids, terpenoids, triterpenoid, carbohydrate, anthroquinone, polyphenol, glycoside bioactive compound was isolated by column chromatography technique. The collected flavonoid fractions was purified by thin layer chromatography. FTIR, HPLC and NMR studies were carried out to find the structure of bioactive compound Quercetin. ${ }^{1} \mathrm{H}-$ NMR and ${ }^{13} \mathrm{C}-$ NMR that reveals the structure of flavonoids. The compound was identified as 3, 3', 4', 5, 7 pentahydroxyflavanone by ${ }^{1} \mathrm{H}$ - NMR and ${ }^{13} \mathrm{C}-\mathrm{NMR}$. All these data obtained in the present investigation supported the rich source of phytochemicals preent in J.gendarussa leaves extract and therby traditional claim associated with $J$. gendarussa literature.
\end{abstract}

Keywords- Justicia gendarussa, phytochemical, FTIR, HPLC and NMR

\section{INTRODUCTION}

World Health Organization estimate over $80 \%$ of the people in developing countries depend on traditional medicines for their primary health care ${ }^{1}$. India is one of the largest producers of medicinal herbs and is rightly called the botanical garden of the world as it is sitting on a gold mine of well-recorded and traditionally well practiced knowledge of herbal medicine. Nearly 17,000 species of Indian flora, and 7500 species of higher plants are reported to possess medicinal value and in other countries it is projected about $7 \%$ and $13 \%$. There are estimated to be around 25,000 effective plant-based formulations, used in folk medicine and known to rural communities in India ${ }^{2}$.

The search for new molecules, nowadays, has taken a slightly different route where the science of ethno botany and ethno pharmacognosy are being used as guide to lead the chemistry towards different sources and classes of compounds ${ }^{3}$. Plant derived natural products hold great promise for discovery and development of new pharmaceuticals ${ }^{4}$.

The search for biologically active compounds from natural sources has always been of great interests to researchers looking for new sources of drugs useful in various diseases. The indigenous population has developed vast knowledge on the uses of plant as traditional medicines to protect themselves and their crops, plants are known to contain numerous biologically active compounds which possess curative properties. Within a decade, there were a number of dramatic advances in analytical techniques including TLC, UV, NMR, FTIR, HPLC, HPTLC and GCMS that were powerful tools for separation, identification and structure determination of phytochemicals ${ }^{5}$. Biological screening is necessary to provide a scientific basis for validating the traditional utilization of medicinal plants. A great number of screening programs are going on worldwide for new plant based bioactive molecules. NMR, HPLC and FTIR can be used to study traditional medicines and characterize the compound of interest. In the present study to investigate the bioactive compound in J. gendarussa leaves.

\section{MATERIALS AND METHODS}

\section{Collection of Plant materials:}

The leaves of Justicia gendarussa were collected from Kadukaval in January 2018 Thanjavur, Tamil Nadu, India. Identified with the help of Flora in Carnatic ${ }^{6}$.

\section{Preparation of alcoholic extract:}

The leaves of $J$. gendarussa were first washed and dust was removed. The leaves were washed several times with 
distilled water to remove the traces of impurities from the leaves. The leaves were dried at room temperature and coarsely powdered. The powder was extracted with aqueous and $70 \%$ methanol for 24 hours. The extract was stored in refrigerator until used.

\section{Phytochemical screening:}

Chemical tests were carried out on the alcoholic extract and on the powdered specimens using standard procedures to identify the constituents as described by Sofowara ${ }^{7}$, Trease and Evans ${ }^{8}$ and Harborne ${ }^{9,10}$.

\section{Quantitative assay:}

Determination of total phenols by spectrophotometric method. Flavonoid determination by the method ${ }^{11}$.

\section{HPLC Analysis:}

Flavonoids were analyzed by using HPLC method ${ }^{12}$.

\section{Column Chromatography:}

Separation of flavonoid compound using in column chromatography adopted by the method $^{13}$.

\section{Thin layer chromatography :}

Thin layer Chromatography is based upon the principles of column and partition Chromatography. A thin layer of the stationary phase is formed on a suitable flat surface, such as glass. Separation of a mixture in this case is achieved over a thin layer of silica gel to which they are absorbed by different physical forces ${ }^{9,10}$.

\section{Fourier Transform Infrared (FTIR) spectroscopic analysis}

FTIR spectrophotometer (Perkin Elmer Spectrophotometer system, USA) used to investigation of spectrum. A small amount of plant extract was respectively placed directly on sample holder of the infrared spectrometer with constant pressure applied and data of infrared absorbance, collected over the wave number ranged from $4000 \mathrm{~cm}^{-1}$ to $400 \mathrm{~cm}^{-1}$ and computerized for analyses by using the 21 CFR part 11 software. The reference spectra were acquired from the cleaned blank crystal prior to the presentation of each sample replicate. The peak values of FTIR were recorded.

\section{NMR Spectroscopy}

After the separation of plant extract to fractions using Column chromatography, Thin Layer chromatography was used for further purification of collected fraction. The NMR experiment was carried out in BRUKER-AMX400 $\mathrm{MHz}$ instrument with $5 \mathrm{mg}$ of purified compound in DMSO were used for ${ }^{1} \mathrm{H}$ NMR and ${ }^{13} \mathrm{C}$ NMR spectra recorded. Tetra Methyl Silane is used as the internal standard and chemical shifts are expressed in ppm.

\section{RESULTS}

\section{Qualitative analysis}

The phytochemical characters of the leaves of $J$. gendarussa investigated and summarized in Table 1 and Fig 2. The phytochemical screening aqueous extract of $J$. gendarussa leaves shows that the presence of saponin, flavonoids, steroids, terpenoids, triterpenoids, alkaloids, carbohydrate, anthroquinone, polyphenol, glycoside were absence of tannin, plobatannins and protein. Methanol extract of leaves $J$. gendarussa showed that the presence of tannin, saponin, flavonoids, steroids, terpenoids, triterpenoids, alkaloids, carbohydrate, anthroquinone, polyphenol, glycoside were absence of plobatannins and protein.

\section{Column chromatography}

Column chromatography of J. gendarussa leaves extract afforded 3 fractions. The result of chromatographic separation is given in Table 2, Fig 3 and Fig 4.

\section{Thin Layer Chromatography}

The presences of secondary metabolites in the extracts were detected by TLC using suitable reagents. The presence of flavonoid was detected by information of pale yellow colour spot in the positive reaction by exposure of ammonia. In the present study flavonoid was in the leaves detected of $J$. gendarussa (Table 3).

\section{HPLC}

HPLC study reveals the presence of quercetin in the leaves of $J$. gendarussa (Table 4 and Fig 6).

\section{Fourier Transform Infra-Red Spectroscopy analysis}

The FTIR spectrum of the J. gendarussa leaf extract source pronounced absorbance was recorded in the region between 4000 and $400 \mathrm{~cm}^{-1}$. The peak indicates alcoholic and phenolic groups, alkenes (C-H strech stretch), alkenes (C-H stretch), carboxylic acids (O-H strech), alkenes $(-\mathrm{C}=\mathrm{C}-$ stretch$)$, alkynes $(\mathrm{C}=\mathrm{C}-$ stretch $)$, aromatics and alkenes (C-C stretch (in-ring) and $\mathrm{C}-\mathrm{H}$ bend), aromatics $(\mathrm{C}$ $\mathrm{C}$ stretch (in-ring), aromatic amines (C-N stretch), alkynes (C-O stretch and C-N stretch), 1049.33 indicates aliphatic amines (C-N stretch) Table 5, Fig 7.

\section{NMR spectrum leaves of $\boldsymbol{J}$. gendarussa extract}

Nuclear magnetic resonance (NMR) spectroscopy has evolved as one of the most powerful analytical techniques. It allows the visualization of single atoms and molecules in various media in solution as well as in solid state. NMR is nondestructive and gives molar response that allows structural elucidation and quantification simultaneously. Magnetic interactions between NMR active nuclei along covalent bonds result in spin-spin couplings. Through space interactions can be detected using the 
Nuclear Overhauser Effect (NOE). Both these interactions facilitate the three dimensional structure elucidations. One dimensional and two dimensional NMR data can be collected. The 1D NMR experiments are 1H, 13C, 31P, 19F, etc. The 1D NMR techniques will give information regarding the chemical shifts, spin-spin couplings and intensities. The chemical shifts will give the information regarding environment of the protons. Nuclei which are close to one another exert an influence on each other's effective magnetic field. This effect shows up in the NMR spectrum when the nuclei are non-equivalent. If the distance between non-equivalent nuclei is less than or equal to three bond lengths, this effect is observable. This effect is called indirect spin-spin coupling. The intensities will give the relative number of protons under the peak. The 2D NMR experiments are COSY, TOCSY, HSQC, HMBC, NOESY, ROESY, etc. These 2D experiments provide information regarding through bond or through space interactions.

The intensity or the integral of a signal is considered to be the area under that signal. The comparison of the signal intensities in a spectrum will give the ratios of the protons in the molecule. If there are multiples in a spectrum, the whole group of peaks should be integrated. Just like the chemical shifts and indirect spin-spin couplings, the signal intensities are also important for the structure determination. The signal intensities will help in the quantification of mixtures. In principle, the intensities of carbon-13 signals can also be used to infer the number of carbons responsible for the signal. Practically, the low abundance and sensitivity of the carbon-13 isotope will affect the quantification of number of carbons in a molecule. Due to this reason the carbon signals are generally not integrated in 13C NMR spectrum. The quantification of carbon-13 signal can be made possible with high digital resolution, suppression of NOE, a pulse repetition rate that is not too fast and small spectral width and high pulse power. The one dimensional NMR spectra have two dimensions, the abscissa and the ordinate. The abscissa corresponds to the frequency axis and the ordinate gives the signal intensities. But, in two dimensional (2D) NMR spectra, both the abscissa and the ordinate represent frequency axes; the third dimension gives the intensities. In the 2D J-resolved NMR spectrum, the chemical shifts will be plotted along one of the axes and the coupling constants along the other dimension. If both axes are chemical shifts, then it is called 2D (shift) correlated NMR spectrum. Most often the shift correlated 2D NMR data is used in structure elucidation. The correlations could be homo nuclear $(\mathrm{H} 1-1 \mathrm{H})$ or hetero nuclear $(1 \mathrm{H} / 13 \mathrm{C})$ (Table 5).

\section{${ }^{13} \mathrm{C}$-NMR spectrum}

Supporting evidence for the structure of the glycoside was provided by the analysis of ${ }^{13} \mathrm{C}$-NMR data and a complete assignment. It was characterized as 2-(3, 4Dihydroxyphenyl)-3, 5, 7-trihydroxy-4H-1-benzopyran-4one (quercetin) (Fig 8).

\section{${ }^{1}$ H-NMR spectrum}

In ${ }^{1} \mathrm{H}-\mathrm{NMR}$ spectrum $(500 \mathrm{MHz}, \mathrm{MeOD})$ the A ring protons at C-6 and C-8 appear as $\delta 6.28$ and $\delta 6.43 p p m$ respectively. A two proton singlet at $\delta 7.67$ assigned to $\mathrm{H}$ 2' and H-6' (Mizuno et al., 1992). The proton at C-5' appears as $\delta 6.95 \mathrm{ppm}$ as doublet (Fig 9).

Table.1: Phytochemical screening leaves of J. gendarussa

\begin{tabular}{|l|l|c|c|}
\hline S. No & Phytochemicals & Methanol extract & Aqueous Extract \\
\hline 1 & Tannin & + & - \\
\hline 2 & Phlobatannin & - & - \\
\hline 3 & Saponin & + & + \\
\hline 4 & Flavonoids & + & + \\
\hline 5 & Steroids & + & + \\
\hline 6 & Terpenoids & + & + \\
\hline 7 & Triterponids & + & + \\
\hline 8 & Alkaloids & + & + \\
\hline 9 & Carbohydrate & + & + \\
\hline 10 & Protein & - & - \\
\hline 11 & Anthroquinone & + & + \\
\hline 12 & Polyphenol & ++ & + \\
\hline 13 & Glycoside & + & + \\
\hline
\end{tabular}

(+) Presence, (++) highly presence and (-) Absence 
Table.2: Separation of fractions from column chromatography

\begin{tabular}{|r|c|c|c|}
\hline S. No. & Eluents & Number of fraction(s) & Nature of fractions \\
\hline 1. & Hexane & 01 & Yellow \\
\hline 2. & Chloroform & 01 & White \\
\hline 3. & $\mathrm{CHCl}_{3}: \mathrm{MeOH}(7: 1)$ & 01 & Greenish Yellow \\
\hline
\end{tabular}

Table.3: Analysis of flavonoid by TLC in the leaves of $\boldsymbol{J}$.gendarussa

\begin{tabular}{|c|c|c|c|}
\hline Phytoconstituents & Rf Value & Results & Literature (Gordana, 2003) \\
\hline Flavonoid & $8.2 / 9.4$ & 0.85 & Flavonoid derivatives $(\mathrm{Rf}=0.90)$ \\
\hline
\end{tabular}

Table.4: Compound identified HPLC in the leaves of J.gendarussa

\begin{tabular}{|c|c|c|c|c|c|c|}
\hline Peak\# & Ret. Time & Area & Height & Area\% & Height \% & $\begin{array}{c}\text { Compounds identified by } \\
\text { literature (Gupta Mradu et } \\
\text { al., 2012) }\end{array}$ \\
\hline 1 & 3.063 & 126083 & 2000 & 93.549 & 90.992 & Quercetin \\
\hline 2 & 14.752 & 8694 & 198 & 6.451 & 9.008 & Unknown (impurity) \\
\hline Total & - & 134777 & 2198 & 100.000 & 100.000 & - \\
\hline
\end{tabular}

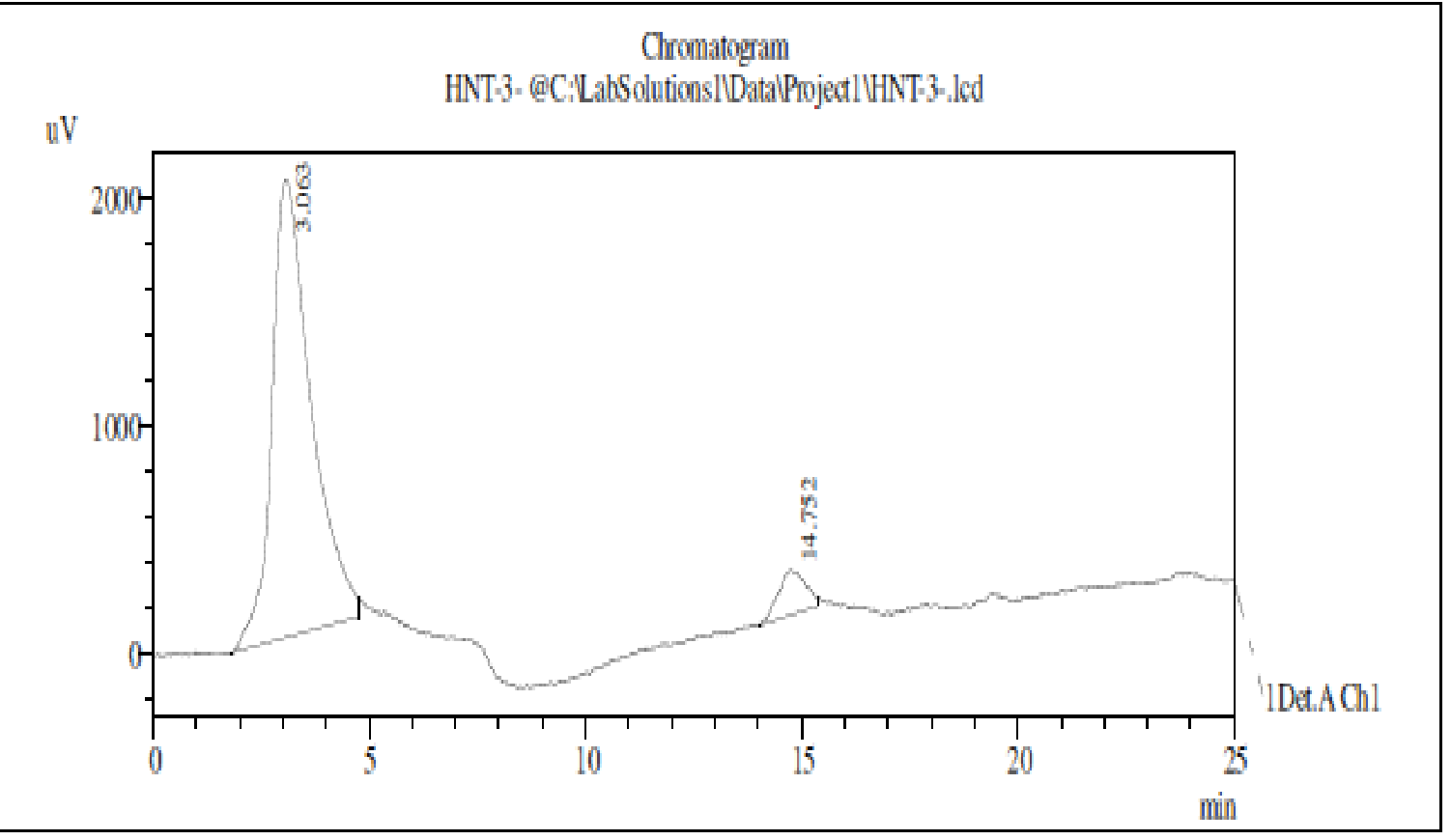

Fig.6: Analysis of HPLC in the leaves of J. gendarussa

Table.5: FTIR Peak Values of leaves of J.gendarussa

\begin{tabular}{|l|l|l|}
\hline \multicolumn{1}{|c|}{ Peak Value } & \multicolumn{1}{|c|}{ Bond } & \multicolumn{1}{c|}{ Functional group } \\
\hline 3412.70 & O-H stretch, H-bonded & Alcohols, phenols \\
\hline 2968.71 & O-H stretch & Carboxylic acids \\
\hline 2951.19 & O-H stretch & Carboxylic acids \\
\hline
\end{tabular}




\begin{tabular}{|l|l|l|}
\hline 2925.07 & O-H stretch & Carboxylic acids \\
\hline 2843.59 & O-H stretch & Carboxylic acids \\
\hline 2866.52 & O-H stretch & Carboxylic acids \\
\hline 2524.13 & O-H stretch & Carboxylic acids \\
\hline 1649.35 & - C-C- stretch & Alkenes \\
\hline 1454.31 & C-H bend & Alkanes \\
\hline 1412.59 & C-C stretch (in-ring) & Aromatics \\
\hline 1112.14 & C-H wag (-CH2X) & Alkyl halides \\
\hline 1053.29 & C-N stretch & Aliphatic amines \\
\hline 1017.78 & C-N stretch & Aliphatic amines \\
\hline 1031.31 & C-N stretch & Aliphatic amines \\
\hline 691.97 & C-H "oop" & Aromatics \\
\hline
\end{tabular}

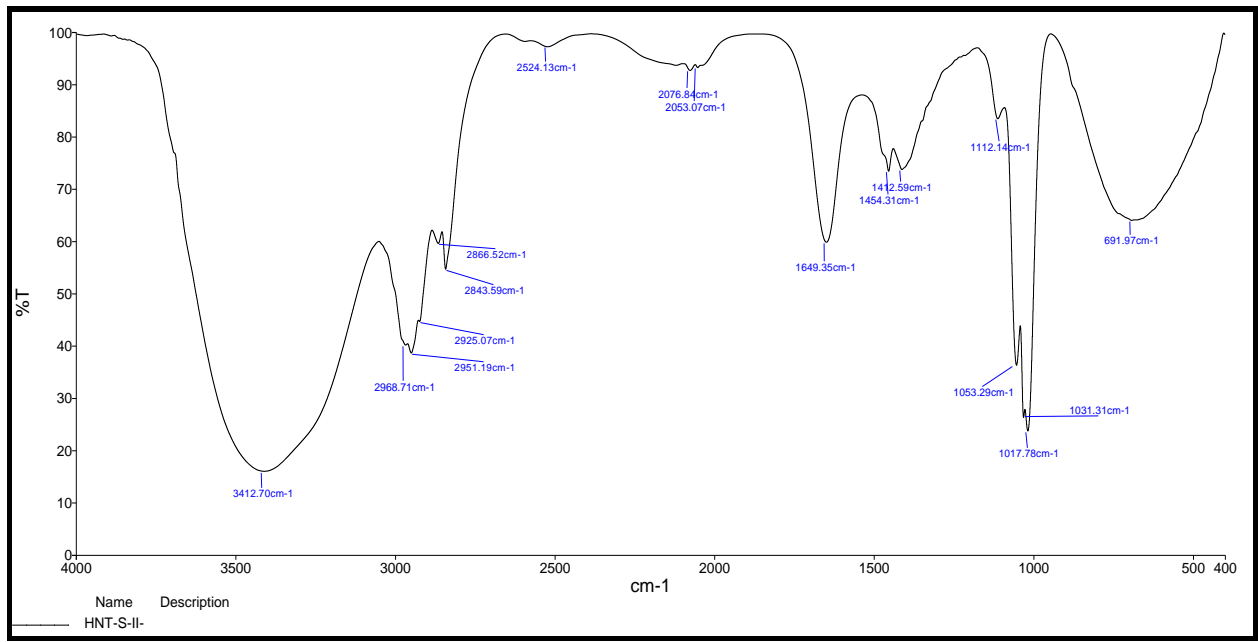

Fig.7: FTIR spectrum of $\boldsymbol{J}$. gendarussa leaves

Table.6: ${ }^{13} \mathrm{C}$-NMR DATA AND THEIR ASSIGNMENT OF QUERCETIN

OBTAINED BY THE REFERENCES

(Harborne and Williams, 1992; Guvenalp and Omur, 2005; Guvenalp and Nurcan, 2006).

\begin{tabular}{|c|c|c|c|}
\hline \multirow{2}{*}{ Carbon } & \multicolumn{3}{|c|}{ QUERCETIN } \\
\cline { 2 - 4 } & Literature & Reference Standard & Plant extract \\
\hline 2 & 147.90 & 147.65 & 146.10 \\
\hline 3 & 137.20 & 135.68 & 137.18 \\
\hline 4 & 177.30 & 175.79 & 177.24 \\
\hline 5 & 162.50 & 160.67 & 162.03 \\
\hline 6 & 99.30 & 98.12 & 99.26 \\
\hline 7 & 165.70 & 163.83 & 165.98 \\
\hline 8 & 94.40 & 93.29 & 94.30 \\
\hline 9 & 158.20 & 156.08 & 157.11 \\
\hline 10 & 104.40 & 102.96 & 103.02 \\
\hline $1^{\prime}$ & 124.10 & 121.90 & 121.80 \\
\hline $2^{\prime}$ & 116.00 & 115.55 & 116.11 \\
\hline $3^{\prime}$ & 146.20 & 146.75 & 146.10 \\
\hline $4^{\prime}$ & 148.70 & 147.65 & 148.50 \\
\hline $5^{\prime}$ & 116.20 & 115.02 & 116.11 \\
\hline $6^{\prime}$ & 121.60 & 121.90 & 121.80 \\
\hline & & & \\
\hline
\end{tabular}




\section{Finding compound}

Based on this the data has been characterized as Quercetin (Molecular Formula: $\mathrm{C}_{15} \mathrm{H}_{10} \mathrm{O}_{7}$ )

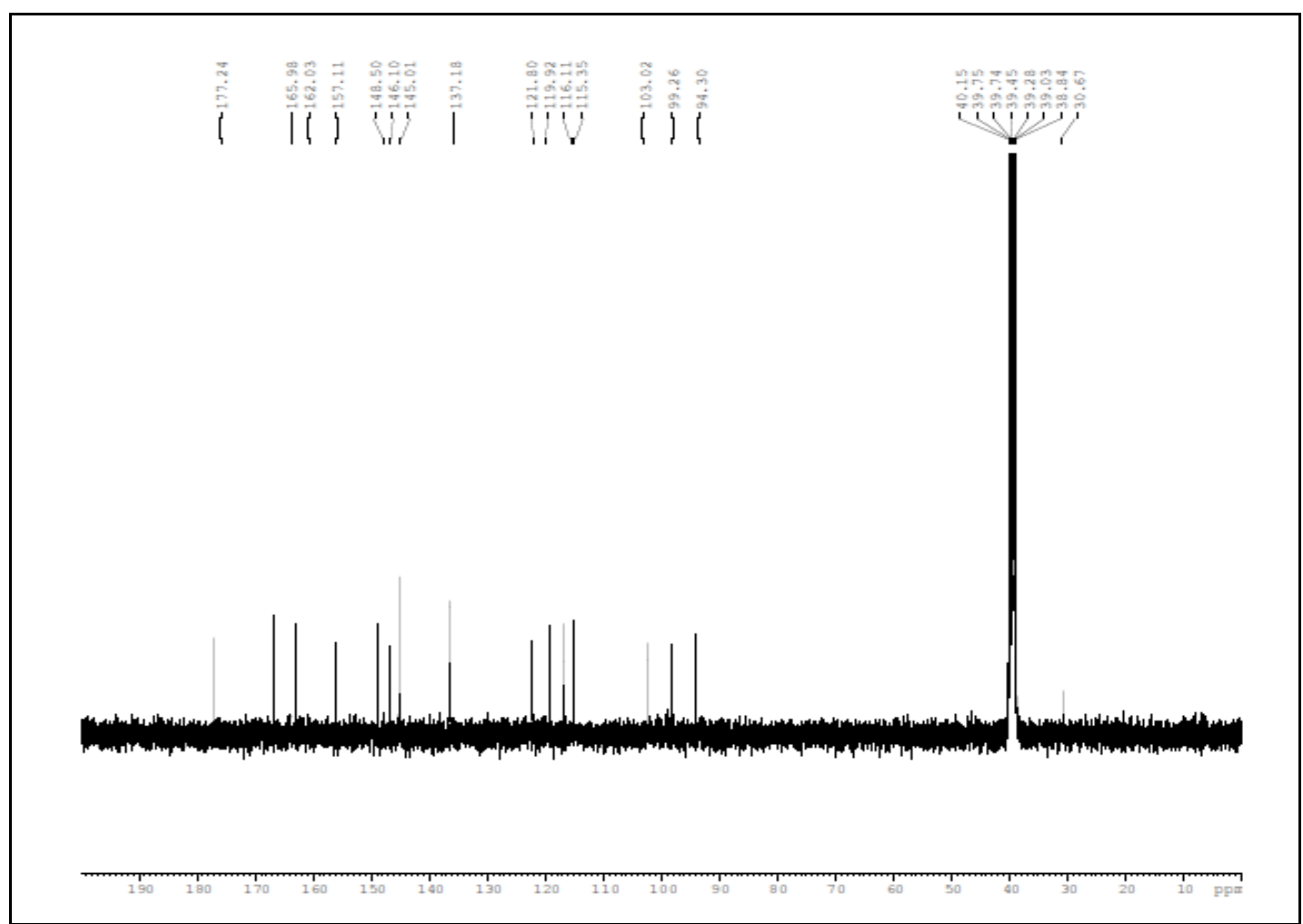

Fig $8:{ }^{13} \mathrm{C}$ - NMR spectrum J. gendarussa leaves extract

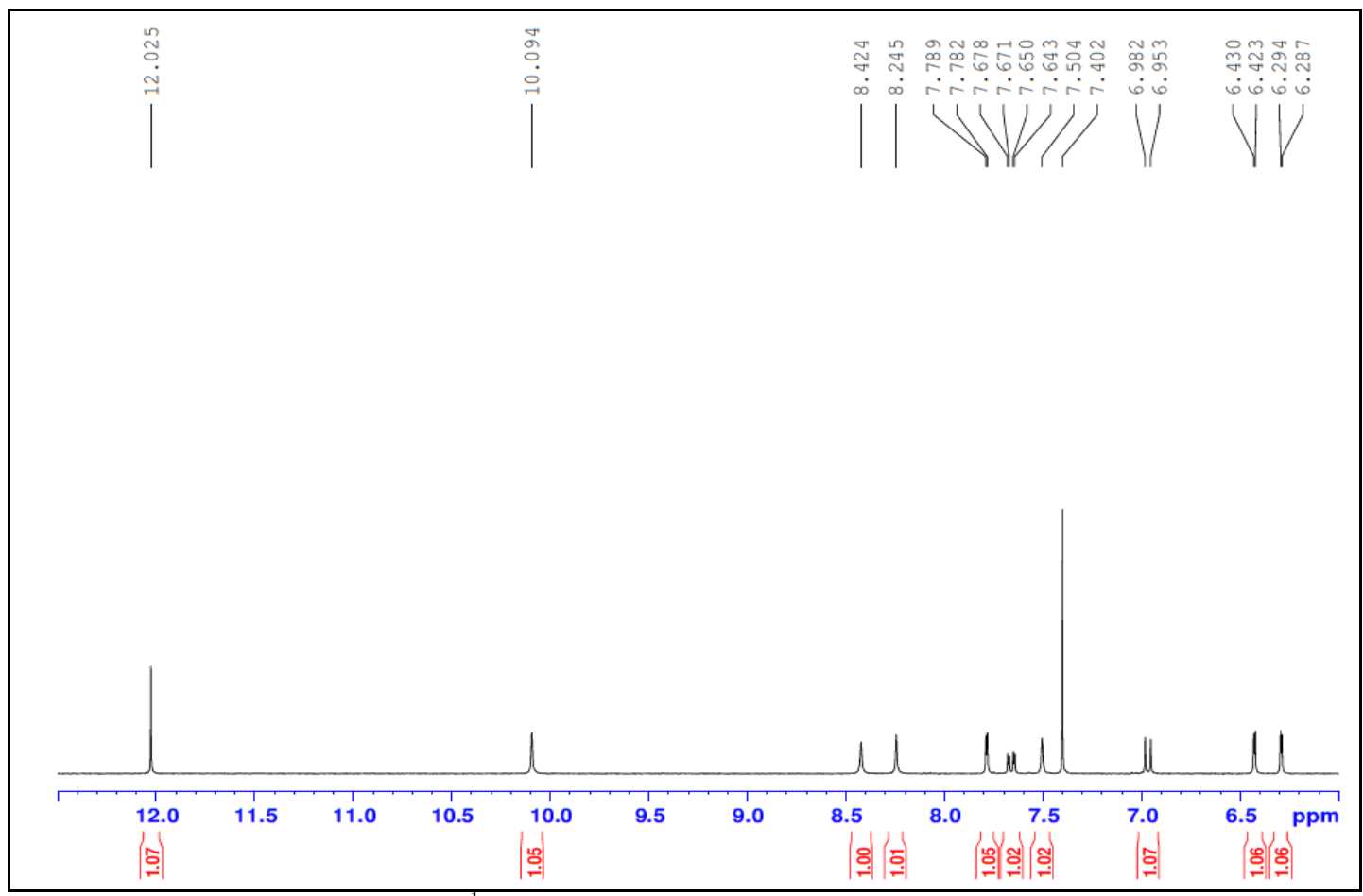

Fig 9: ${ }^{1} \mathrm{H}$-NMR spectrum $J$. gendarussa leaves extract 


\section{DISCUSSION}

Phytochemicals in plant material have raised interest among scientists, food manufacturing and pharmaceutical industry, as well as consumers for their roles in the maintenance of human health. Phytochemicals are the bioactive, non-nutrient, and naturally occurring plant compounds found in fruits, vegetables, and whole grains. They can be categorized into various groups, i.e., polyphenols, organo sulfur compounds, carotenoids, alkaloids, and nitrogen-containing compounds. Many phytochemicals are potent effectors of biologic processes and have the capacity to influence disease risk via several complementary and overlapping mechanisms ${ }^{14}$. The phytochemical screening of aqueous extract of $J$. gendarussa leaves showed that the presence of flavonoids, terepenoids, steroids, saponins, triterpenoids, phenolics, alkaloids, carbohydrate, anthriquinone and glycosides while phlobatannins, tannin and protein were absent.

Abuzar et al. ${ }^{15}$ reported the phytochemical analysis of Heliotropium dasycarpum and evaluating the presence of secondary metabolites like alkaloids and cardiac glycosides while the saponins, anthroquinone, glycoside and tannins were absent in the plant extract.

A simple, accurate, and reproducible high-performance liquid chromatography (HPLC) method has been developed and validated for the quantification of flavonoids ${ }^{16}$. Quercetin were confirmed in Justicia gendarussa using HPLC $^{17}$ were carried out to characterize the phenolic acids and flavonoids in methanolic extracts of Withania somnifera leaves by HPLC. Five phenolics (gallic, syringic, benzoic, p-coumaric and vanillic acids) and three flavonoids (catechin, kaempferol and naringenin) have been identified in Withania somnifera leaves. Similarly catechol, gallic acid, ellagic acid, and catechin of compounds were identified in Cissus vitiginea leaves among the four compounds of this present study.

Paranthaman et al. ${ }^{18}$ Investigated the GC-MS analysis of phytochemicals and simultaneous determination of flavonoids in Amaranthus caudatus by RP-HPLC. A sensitive and selective high performance liquid chromatography method (HPLC) for simultaneous analysis of following five flavonoids like gallic acid (GA), caffeic acid (CA), rutin (RU), ferulic acid (FA) and quercetin (QU) in Amaranthus caudatus leaves. The results demonstrated that the Cissus vitiginea leaves were separately extracted and analyzed using HPLC method. The contents of gallic acid $(0.083 \mu \mathrm{g} / \mathrm{gm})$, Caffeic acid $(0.004 \mu \mathrm{g} / \mathrm{gm})$, Rutin $(0.019 \mu \mathrm{g} / \mathrm{gm})$, Quercetin $(0.001 \mu \mathrm{g} / \mathrm{gm})$ and Ferulic acid $(0.001 \mu \mathrm{g} / \mathrm{gm})$ in Cissus vitiginea leaves.

Fourier Transform Infrared (FTIR) Spectroscopy is a rapid, noninvasive, high resolution analytical tool for identifying types of chemical bonds in a molecule by producing an infrared absorption spectrum that is like a molecular fingerprint ${ }^{19}$. FTIR has been shown to be a valuable tool for differentiating, classifying and discriminating closely related microbial strains, plants and other organisms ${ }^{20,21}$. It is one of the most widely used methods to identify the chemical constituents and elucidate the structural compounds and has been used as a requisite method to identify medicines in pharmacopoeia of many countries.

It is well known that the medicinal materials comprise hundreds of components and produce their curative effects through mutual effects of many ingredients, so the limited numbers of specific components cannot availably reflect the real qualities of the herbal medicines. Therefore, an effective and inexpensive analysis method to entirely monitor the whole constituents of the medicinal materials and their corresponding extract products is required ${ }^{22}$.

FTIR has played a vital role in pharmaceutical analysis in recent years ${ }^{23}$. FTIR spectroscopy is a physicochemical analytical technique that does not determine concentrations of individual metabolites but provides a snapshot of the metabolic composition of a tissue at a given time ${ }^{19}$. The FTIR method measures predominantly the vibrations of bonds within chemical functional groups and generates a spectrum that can be regarded as a biochemical or metabolic "fingerprint "of the sample ${ }^{24}$.

FTIR has proven to be a valuable tool for the characterization and identification of compounds or functional groups (chemical bonds) present in an unknown mixture of plants extract ${ }^{25,26}$. FTIR spectrum of the $J$. gendarussa leaf extract was pronounced absorbance was recorded in the region between 4000 and $400 \mathrm{~cm}^{-1}$. The peak indicates alcoholic and phenolic groups, alkenes $(\mathrm{C}-\mathrm{H}$ strech stretch), alkenes (C-H stretch), carboxylic acids (O-H strech), alkenes $(-\mathrm{C}=\mathrm{C}-$ stretch $)$, alkynes $(\mathrm{C}=\mathrm{C}-$ stretch $)$, aromatics and alkenes (C-C stretch (in-ring) and $\mathrm{C}-\mathrm{H}$ bend), aromatics (C-C stretch (in-ring), aromatic amines (C-N stretch), alkynes C-O stretch and C-N stretch), 1049.33 indicates aliphatic amines $\mathrm{C}-\mathrm{N}$ stretch).

Karpagasundari and Kulothungan ${ }^{27}$ screened the bioactive components of Physalisminima leaves have been evaluated using UV-visible and FTIR. The UV-visible profile showed the peaks at $315.09 \mathrm{~nm}, 408.09 \mathrm{~nm}$ and $676.50 \mathrm{~nm}$ with the absorption 0.247, 0.106 and 0.003 respectively. The results of FTIR analysis confirmed the presence of phenol, alkanes, aldehyde, secondary alcohol, amino acid, aromatic amines and halogen compound. The results of this study offer a platform of using Physalisminima leaves as herbal alternative for various diseases. 
Nuclear magnetic resonance (NMR) spectroscopy is usually the method of choice for natural product structure determination and it is not surprising that this powerful technique has come to the fore in plant metabolomics. The data requirements for metabolomics are the qualitative and quantitative analyses of the maximum number of metabolites in the highest achievable throughput. Most metabolomics laboratories deploy a range of spectroscopic technologies but use of NMR spectroscopy, particularly as a first pass screen, has a number of advantages over other analytical platforms currently being used. Sample preparation is relatively simple when compared to other analytical methods and a high sample throughput with little instrument drift is readily achieved. NMR is not discriminatory unlike certain mass spectrometry methods that rely on the prior derivatization of metabolites or the ability of them to ionize. Metabolite screening requires maximum sensitivity with a broad compound coverage. Based on ${ }^{1} \mathrm{H}$ and ${ }^{13} \mathrm{C}$ data has been characterized as Quercetin (Molecular Formula: $\mathrm{C}_{15} \mathrm{H}_{10} \mathrm{O}_{7}$ ).

Sumit Arora and Prakash Itankar ${ }^{28}$ showed the extraction, isolation and identification of flavonoid from Chenopodium album aerial parts. The flavonoids contained in C. album aerial parts were extracted, identified and characterized. Sequential soxhlet extraction was subjected to preliminary screening and flavonoid quantification. The results showed that maximum yield of the flavonoid $(7.335 \mathrm{mg} / \mathrm{g})$ were obtained from acetone extract. This acetone extract was subjected to flash chromatography for isolation of flavonoid. Characterization of isolated flavonoid was done by UV, IR, 1H \& 13C NMR and MS. On the basis of chemical and spectral analysis structure was elucidated as 2-(3, 4-dihydroxyphenyl)-3, 5, 7-trihydroxy-4H-chromen-4one, a flavonoid.

Ahmadu et al. ${ }^{29}$ examined flavonoid glycosides from Byrsocarpus coccineus leaves. The bioactive ethyl acetate and N-butanol soluble parts of an ethanolic extract of Byrsocarpus coccineus leaves was subjected to column chromatography over silica gel G $(60-120 \mu)$ and repeated purification of the flavonoid rich fraction over sephadex LH20 eluted with methanol led to the isolation of three flavonoid glycosides identified as quercetin 3-O- $\alpha$ arabinoside (I), quercetin(II) and quercetin 3- $\beta$-D-glucoside.

Present study concluded that FTIR, HPLC and NMR studies were carried out to find the structure of bioactive compound Quercetin. ${ }^{1} \mathrm{H}-\mathrm{NMR}$ and ${ }^{13} \mathrm{C}-\mathrm{NMR}$ that reveals the structure of flavonoids. The compound was identified as 3, 3', 4', 5, 7 - pentahydroxyflavanone by ${ }^{1} \mathrm{H}$ NMR and ${ }^{13} \mathrm{C}-\mathrm{NMR}$. All these data obtained in the present investigation supported by traditional claim associated with J. gendarussa literature. Further biological studies along with chemical characterization of the separated compounds will have the way for a better understanding of the bioactive product and its subsequent application in disease.

\section{REFERENCES}

[1]. D. Shankar, B. Majumdar, Beyond the biodiversity convention: The challenges facing the biocultural heritage of India's medicinal plants. In: Medicinal plants for forest conservation and health care, (Non-wood forest products Services), 1993, 11, 163.

[2]. Sunita Verma. Medicinal plants used in cure of skin diseases. Advances in Applied Science Research, 2016, 7(3), 65-67

[3]. F.A. Gurib, Medicinal plants: Traditions of yesterday and drugs of tomorrow. Mol. Aspects Med., 2006, 27(1), 1-93.

[4]. J. McChesney, S. Venkataraman, J. Henri, Plant al products: Back to the future 2007.

[5]. Roberts J.K.M and J.H. Xia. High-resolution NMR methods for study of higher plants, Methods Cell Biol. 1995, 49, 245-258.

[6]. K.M. Matthew, The flora of the Tamilnadu Carnatic, Volume 1. Front Cover. Rapinat Herbarium, St. Joseph's College, - Botany 1983.

[7]. A. Sofowara, Medicinal plants and Traditional medicine in Africa. Spectrum Books Ltd, Ibadan, Nigeria, 1993, 289.

[8]. G.E. Trease, W.C. Evans, Pharmacognsy. $11^{\text {th }}$ Brailliar Tiridel Can. Macmillian publishers. 1989.

[9]. J.B. Harborne, Phytochemical Methods; A guide to modern techniques of plant Analysis. $2^{\text {nd }}$ Edition, London New York. 1973, 49-188.

[10]. J.B. Harborne, Phytochemical Methods.A Guide to Modern Technique of Plant analysis. London: Chapman and Hall, 1984, 78-210.

[11]. B.A. Bohm, R. Kocipai-Abyazan, Flavonoids and condensed tannins from leaves of Hawaiian vaccinium vaticulatum and $V$. calycinium. Pacific Sci. 1994, 48, 458-463.

[12]. Weerasak Samee, Suwanna Vorarat. Simultaneous determination of gallic acid, catechin, rutin,ellagic acid and quercetin in flower extracts of Michelia alba, Caesalpinia pulcherrima and Nelumbo nucifera by HPLC. Thai Pharm Health Sci J, 2007, 2, 131-137.

[13]. Javed Intekhab, Mohammad Aslam. Isolation of a flavonoid from the roots of Citrus sinensis. Malaysian Journal of Pharmaceutical Sciences, 2009, 7(1), 1-8.

[14]. J.W. Lampe, J.L. Chang, Interindividual differences in phytochemical metabolism and disposition. Seminars in cancer biology, 2007, 17( 5), 347-353.

[15]. M. Abuzar Ghaffari, S. Bano, K. Hayat, Antimicrobial and phytotoxic effects of the plant Heliotropium dasycarpum L. International Journal of Pharma and Bio Sciences, 2013, 4(4), 339 -345 .

[16]. L.R. Snyder, J.J. Kirkland, "Introduction to Modern Liquid Chromatography" Wiley, New York. 1979.

[17]. Nadia Alam, Monzur Hossain, Ibrahim Khalil Md, Mohammed Moniruzzaman, Siti Amrah Sulaiman, Siew Hua Gan. High catechin concentrations detected in Withania somnifera (ashwagandha) by high performance liquid chromatography analysis. BMC Complementary and Alternative Medicine, 2011, $11,65$.

[18]. R. Paranthaman, P. Praveen kumar, S. Kumaravel, GC-MS Analysis of Phytochemicals and Simultaneous Determination of Flavonoids in Amaranthus caudatus (Sirukeerai) by RP-HPLC. J Anal Bioanal Techniques, 2012, 3(5), 1-5.

[19]. R. Hori, J. Sugiyama, A combined FT-IR microscopy and principal component analysis on softwood cell walls. Carbohydr. Polym., 2003, 52, 449-453.

[20]. S.W. Kim, S.H. Ban, H. Chung, S. Cho, H.J. Chung, P.S. Choi, O.J. Yoo, \& J.R. Liu, Taxonomic discrimination of flowering plants by multivariate analysis of Fourier transform infrared spectroscopy data. Plant Cell Reports, 2004, 23, 246-250.

[21]. N. Janakiraman, S. Sebenzyahaya Sathish, M. Johnson, UV-VIS and FTIR Spectroscopic Studies on Peristrophe bicalyculata 
(Retz.) Nees. Asian Journal of Pharmaceutical and Clinical Research, 2011, 4(4), 125-129.

[22]. H. Liu, S. Sun, G. Lv, K.K.C.Chan, Study on angelica and its different extracts by fourier transform infrared spectroscopy and two-dimensional correlation IR spectroscopy. Spectrochimica Acta Part, 2006, 64, 321-326.

[23]. D.I. Ellis, D. Broadhurst, D.B. Kell, J.J. Rowland, R. Goodacre, Rapid and quantitative detection of the microbial spoilage of meat by Fourier transform infrared spectroscopy and machine learning. Applied and Environmental Microbiology, 2002, 68, 2822-2828.

[24].P.R. Griffiths, J.A. De Haseth, Fourier transform infrared spectroscopy. New York: Wile. 1986.

[25]. T.L. Eberhardt, X. Li, T.F. Shupe, C.Y. Hse, Chinese Tallow Tree (Sapium Sebiferum) utilization: Characterization of extractives and cell-wall chemistry, Wood Fiber Sci., 2007, 39, 319-324.

[26]. K.M. Hazra, R.N. Roy, S.K. Sen, S. Laska, Isolation of antibacterial pentahydroxy flavones from the seeds of Mimusops elengi Linn. Afr. J. Biotechnol, 2007, 6(12), 1446-1449.

[27]. C. Karpagasundari, S. Kulothungan, Analysisof bioactive compounds in Physalisminima leave using GC MS, HPLC, UVVIS and FTIR techniques. Journal of Pharmacognosy and Phytochemistry, 2014, 3(4), 196-201.

[28]. Sumit Arora, Prakash Itankar. Extraction, isolation and identification of flavonoid from Chenopodium album aerial parts. Journal of Traditional and Complementary Medicine, 2018, 1-7.

[29]. A.A. Ahmadu, H.S. Hassan, M.U. Abubakar, I.N. Akpulu, Flavonoid glycosides from Byrsocarpus coccineus leaves. Schum and thonn (Connaraceae). Afr. J. Trad. CAM, 2007, 4(3), 257260. 